\title{
Feasibility of smartphone application to promote physical activity in healthy Omani female adults
}

\author{
N. Al-Anqodi, F. McCullough and A.M. Salter \\ University of Nottingham, Loughborough, Leicestershire, LE 12 5RD, UK.
}

A physically inactive lifestyle is a major concern as it is related to increased non-communicable diseases ${ }^{(1)}$. Like many countries in the Gulf region, Oman has experienced socioeconomic and innovative technologies growth, which maybe resulting in a trend towards a more sedentary daily practice. The prevalence of physical inactivity among Omani adults occurs at $33 \%$ of men and $41 \%$ of women ${ }^{(2)}$. A recent survey reported that physical inactivity of the Omani adult population was the major contributor to the prevalence of overweight and obesity ${ }^{(3)}$. Based on these findings, the aim of the present study was to investigate the feasibility of a mobile application pedometer base to encourage physical activity among the female Omani adult population.

A five-week randomised controlled trial was conducted on 42 Omani females aged 18-55 years living in Oman. Participants were randomised into a control group $(n=21)$ and app group $(n=21)$. The app group was asked to download a smartphone application (Pacer), which is a step-count pedometer. The control group was asked to keep a physical activity log for the entire duration of the study. App data were sent individually to the investigator by email. Both groups were asked to keep a three-day food diary at baseline and the last week of intervention. In order to test the feasibility, data were collected and analysed for the following parameters: mean active time, mean step count and percentage of energy intake from macronutrients. The study was approved by the University of Nottingham Biosciences Ethics Committee. The statistical analysis used SPSS for independent and paired T-tests. Dietary intake was analysed using the Dietplan6 software.

No significant difference noted between the two groups in terms of active time (Table 1). However, the app group showed a significant increase in step count $(\mathrm{P}=0.001)$ and active time $(\mathrm{P}=0.006)$. Additionally, significant dietary differences were noted between the groups at the end of the intervention - the app group reported lower energy intake and carbohydrate intake $(\mathrm{P}=0.04$ and $\mathrm{P}=0.007$, respectively), and the percentage of energy intake from protein was significantly higher $(\mathrm{P}=0.04)$. To conclude, the results of this study demonstrated the effectiveness of a smartphone application in promoting physical activity among Omani female adults living in Oman. There was a trend towards a reduction in carbohydrate intake and increased physical activity. Future studies are needed with longer duration to measure sustainable effects.

Table 1. Mean difference for outcomes in control and app groups at baseline and intervention

\begin{tabular}{|c|c|c|c|c|c|c|}
\hline & & Mean & SD & Mean & SD & \\
\hline \multirow[t]{8}{*}{ Baseline } & Active Time (minutes/day) & 32.7 & 21.3 & 29.68 & 25.96 & 0.69 \\
\hline & Dietary energy (Kcals/day) & $1,142.4$ & 242.5 & 1,373 & 494 & 0.08 \\
\hline & Carbohydrate $(\mathrm{g} / \mathrm{d})$ & 143.7 & 44 & 178.9 & 72 & 0.07 \\
\hline & $\%$ Energy $\mathrm{CHO}$ & 47.3 & 9.9 & 48.2 & 7.7 & 0.75 \\
\hline & Protein $(g / d)$ & 50.9 & 14.8 & 50.7 & 17 & 0.96 \\
\hline & $\%$ Energy protein & 17.9 & 3.4 & 15 & 2.7 & $0.007 *$ \\
\hline & Fat $(\mathrm{g} / \mathrm{d})$ & 44 & 16 & 55.4 & 22.5 & 0.09 \\
\hline & $\%$ Energy fat & 34.8 & 8.7 & 36.6 & 7.3 & 0.49 \\
\hline \multirow[t]{8}{*}{ Intervention } & Active time (minutes/day) & 48.3 & 25.1 & 35.89 & 24.7 & 0.133 \\
\hline & Dietary energy (Kcals/day) & $1,068.6$ & 293.5 & $1,348.8$ & 467.9 & $0.04^{*}$ \\
\hline & Carbohydrate $(\mathrm{g} / \mathrm{d})$ & 126.9 & 35.5 & 175.4 & 66 & $0.009 *$ \\
\hline & $\%$ Energy $\mathrm{CHO}$ & 45.2 & 7.8 & 48.6 & 8.6 & 0.22 \\
\hline & Protein $(\mathrm{g})$ & 49.8 & 14.6 & 52.6 & 14.5 & 0.56 \\
\hline & $\%$ Energy protein & 18.6 & 3.4 & 16.2 & 3.4 & $0.04 *$ \\
\hline & Fat $(\mathrm{g})$ & 43.9 & 17 & 53 & 24.5 & 0.18 \\
\hline & $\%$ Energy fat & 36.1 & 7.2 & 35.1 & 7.3 & 0.68 \\
\hline
\end{tabular}

* Represents significance. P-values ( $\leq 0.05)$; SD (Standard Deviation); CHO (Carbohydrate).

N.Al-Anqodi was supported by an MSc scholarship provided by the Government of Oman.

1. Al-Habsi A \& Kilani H (2014). Sultan Qaboos University Med. J. 15(2), 257-265.

2. Mabry R, Owen N \& Eakin E (2014). Sultan Qaboos University Med. J. 14(2), 170-175.

3. Al Zuhaibi K, McCullough F \& Salter A (2015). Proc. Nutr. Soc. 74(OCE5), E343 doi: 10.1017/S0029665115003900 